\title{
Extraction of total RNA from single-oocytes and single-cell mRNA sequencing of swine oocytes
}

\author{
Katelyn M. Kimble, Sarah E. Dickinson and Fernando H. Biase* (1)
}

\begin{abstract}
Objective: Analyses of single oocytes are essential for a fine dissection of molecular features governing developmental competence. We adapted the phenol-chloroform procedure for the purification of total RNA from single oocytes.

Results: Key modifications include the use of Phasemaker ${ }^{\mathrm{TM}}$ tubes, a second chloroform wash of the aqueous phase, and the precipitation of the RNA with glyclogen in a $200 \mu \mathrm{l}$ micro-centrifuge tube. Assessment of the RNA profile from single oocytes showed distinct peaks for 185 and 285 ribosomal subunits. This approach permitted the extraction of small RNAs from single oocytes, which was evident by the presence of $5 \mathrm{~S}$ and $5.8 \mathrm{~S}$ rRNAs and tRNAs around 122-123 nucleotides long. The amplification of polyadenylated RNA resulted in detectable DNA products ranging from $\sim 500$ to $\sim 5000$ nucleotides. We used the amplified DNA as template for single-cell mRNA-sequencing of five swine oocytes and quantified the expression levels of 9587 genes with complete coverage of transcripts over 10,000 nucleotides in length. The coverage was similar in all oocytes sequenced, demonstrating consistent high RNA quality across samples. We isolated total RNA from single oocytes and demonstrated that the quality was appropriate for single-cell mRNA-sequencing.
\end{abstract}

Keywords: Oocyte, Embryo, RNA sequencing, Single-cell analysis

\section{Introduction}

The abundance of specific ribonucleic acids (RNAs) stored in the female gamete, namely the oocyte, has a direct relationship with the acquisition of developmental competence [1-3]. With the recent advances of next generation sequencing, single-oocyte RNA sequencing data have been generated for mice [4-6], cattle [7], goats [8], and humans [9]. Analyses of single oocytes are essential for a fine dissection of molecular features governing developmental competence, however, technical challenges must be overcome for the generation of data from oocytes compatible with massive single-cell sequencing.

In mammals, the collection of oocytes and downstream preparation for single-cell RNA sequencing is dependent on human handling. The RNA from single oocytes can be

*Correspondence: fbiase@auburn.edu

Department of Animal Sciences, Auburn University, 559 Devall Dr, Auburn, AL 36839, USA obtained through extraction kits [7] or exposed by cellular lysis [10] and used in enzymatic assays. However, three critical problems emerge from current approaches. First, most extraction kits dedicated to limited amounts of RNA work by selecting polyadenylated (polyA + ) RNAs and/or using columns to selectively eliminate cellular debris and small RNAs. Second, it is unclear how much of the RNA is lost when small volumes of eluent are used to recover limited amounts of RNA. Third, oocytes store massive amounts of RNAs, proteins, and lipids. By lysing the cells with detergents, cellular debris can reduce the efficiency of downstream assays such as reverse transcription and polymerase chain reaction [11]. Improving the methods for extraction of RNA from single oocytes is necessary for us to generate next-generation sequencing data from different RNA species [i.e.: micro RNA, or mRNA (messenger RNA)] from single oocytes.

Motivated by the abovementioned limitations, in this report, we describe modifications to the 
phenol-chloroform [12] procedure that made the purification of total RNA from single oocytes possible. We demonstrate that the total RNA is suitable for the preparation of libraries for single cell mRNA. The approach we report can be applied to extract total RNA from single oocytes from any mammalian species.

\section{Main text}

\section{Materials and methods}

No live animals were handled for this study. Swine (Sus scrofa) and bovine (Bos taurus) ovaries were obtained from slaughterhouses and transported to the laboratory in saline solution for the manual aspiration of follicles and collection of cumulus-oocyte complexes. Single germinal vesicle oocytes were manually denuded of cumulus cells (Fig. 1a) and deposited into $5 \mu \mathrm{l}$ of $1 \times$ phosphatebuffered saline (AMRESCO), supplemented with Ribonuclease inhibitor $(0.5 \mathrm{U} / \mu \mathrm{l})$ (AMRESCO), snap frozen in liquid nitrogen, and stored at $-80{ }^{\circ} \mathrm{C}$. For the total RNA extraction from single oocytes (Fig. 1b), the incubation times and centrifugation steps were performed as recommended by the TRIzol ${ }^{\mathrm{TM}}$ (ThermoFisher) and
Phasemaker $^{\mathrm{TM}}$ (ThermoFisher) protocols. We thawed the oocyte by adding $150 \mu \mathrm{l}$ of TRIzol ${ }^{\mathrm{TM}}$ followed by $30 \mu \mathrm{l}$ of chloroform. The mixture was transferred to a Phasemaker $^{\mathrm{TM}}$ tube for centrifugation at $12,000 \times g$ for $5 \mathrm{~min}$ at $4{ }^{\circ} \mathrm{C}$. We then mixed the aqueous solution with $20 \mu \mathrm{l}$ of chloroform followed by a second centrifugation at the same parameters. The aqueous solution was collected and mixed with $1 \mu \mathrm{l}$ of Glycoblue ${ }^{\mathrm{TM}}$ (ThermoFisher) and $150 \mu \mathrm{l}$ of isopropanol in a $200 \mu \mathrm{l}$ tube, then subjected to a centrifugation at $12,000 \times g$ for $10 \mathrm{~min}$ at $4{ }^{\circ} \mathrm{C}$. The RNA pellet was then washed twice with $75 \%$ ethanol followed by centrifugation at $7500 \times g$ for $5 \mathrm{~min}$ at $4{ }^{\circ} \mathrm{C}$. The pellet was air dried and eluted in $1 \mu \mathrm{l}$ of nuclease free water to profile the RNA length distribution in an Agilent 2100 Bioanalyzer (Agilent) following the manufacturer's protocol.

To generate RNA-sequencing data from five swine oocytes, we eluted the RNA pellet in $4 \mu \mathrm{l}$ of a solution containing oligo (dT) (Promega) and deoxynucleotide triphosphates (Promega) to assay full-length polyA+ RNA amplification following the SMART-seq2 procedure [10]. Following cleanup and quantification of the
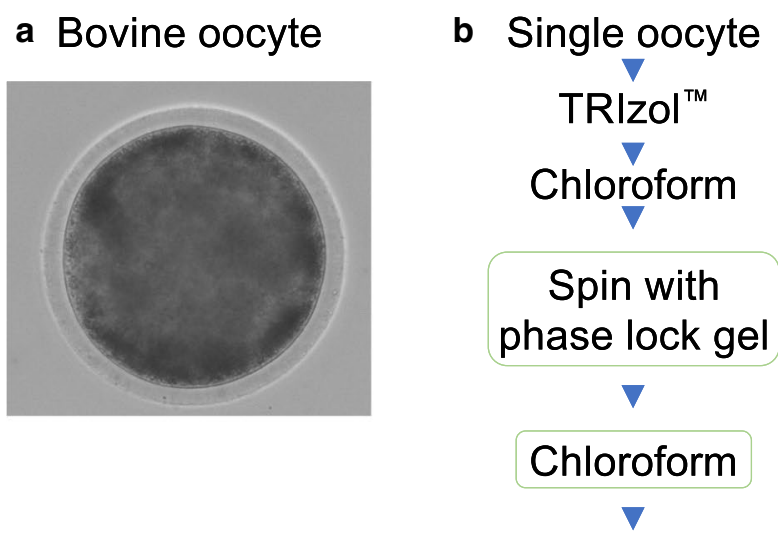

Swine oocyte

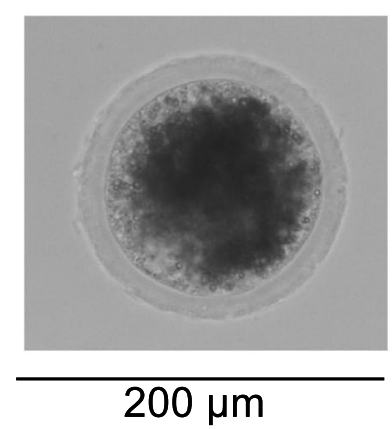

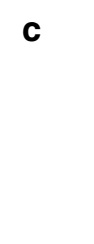
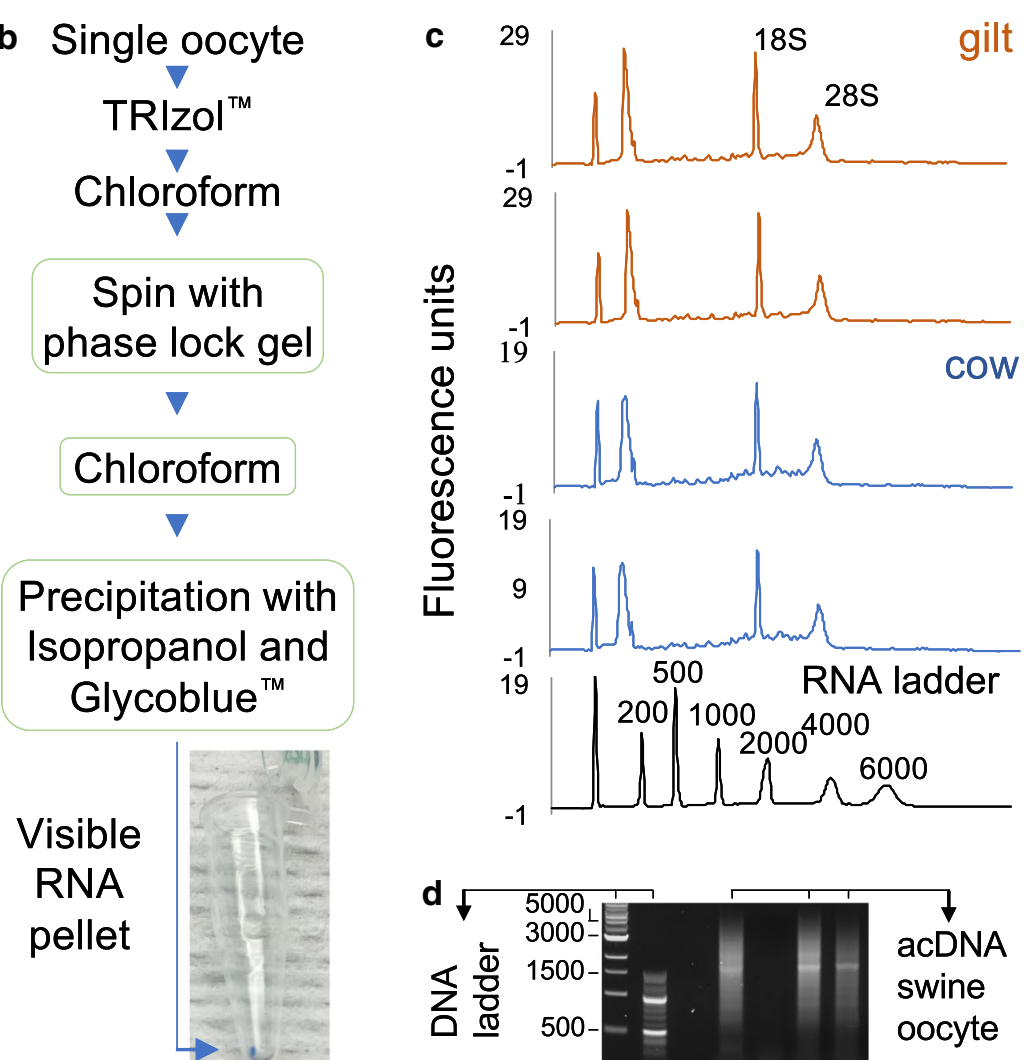

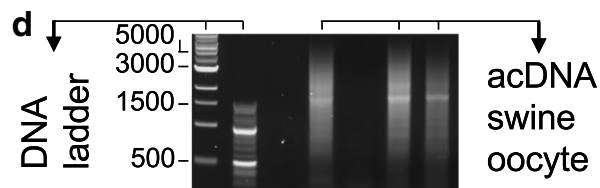

Fig. 1 Total RNA extraction from single oocytes. a Representative images of bovine and swine oocytes. The scale bar is used for both images (b) Diagram of the RNA extraction flow. The green boxes indicate key adaptations to the standard TRIzol ${ }^{\mathrm{TM}}$ protocol. c Representative Bioanalyzer electropherograms of the total RNA extracted from single oocytes, and a ladder for reference. $\mathbf{d}$ Representative full-length cDNA amplification of swine oocytes 
amplified complementary deoxyribonucleic acid (cDNA) on a Qubit 3.0 fluorometer (Thermo Fisher), $1 \mathrm{ng}$ was used as template for next generation sequencing library preparation using Nextera XT DNA library Prep Kit (Illumina, Inc) [10]. The libraries were pooled and assayed on a HiSeq2500 instrument (Illumina, Inc) to generate pairend reads.

The sequences were aligned to swine cDNAs obtained from Ensembl (Sscrofa11.1, release 90) using Bowtie2 [13] with the "-very-sensitive" option. Analyses to characterize the data properties were conducted in R software [14] (Additional file 1).

\section{Results and discussion}

We assessed the distribution of total RNA from single bovine $(\mathrm{N}=25)$ and swine $(\mathrm{N}=22)$ oocytes (Fig. 1c). We observed distinct peaks for $18 \mathrm{~S}\left(\bar{x}_{\text {peak }}=1740\right.$ nucleotides (nt), bovine oocytes; $\bar{x}_{\text {peak }}=1749 \mathrm{nt}$, swine oocytes) and $28 \mathrm{~S}\left(\bar{x}_{\text {peak }}=3481 \mathrm{nt}\right.$, bovine oocytes; $\bar{x}_{\text {peak }}=4523 \mathrm{nt}$, swine oocytes) ribosomal subunits. Additionally, we recorded RNA integrity number values between 5.1 and 7.3.

This procedure allowed us to profile small RNAs of single oocytes. The signal for small RNAs [5S, 5.8S, transfer RNAs (tRNAs)] is commonly observed in preparations using the phenol-chloroform without further column purification [15]. The peaks were averaged on 123 and

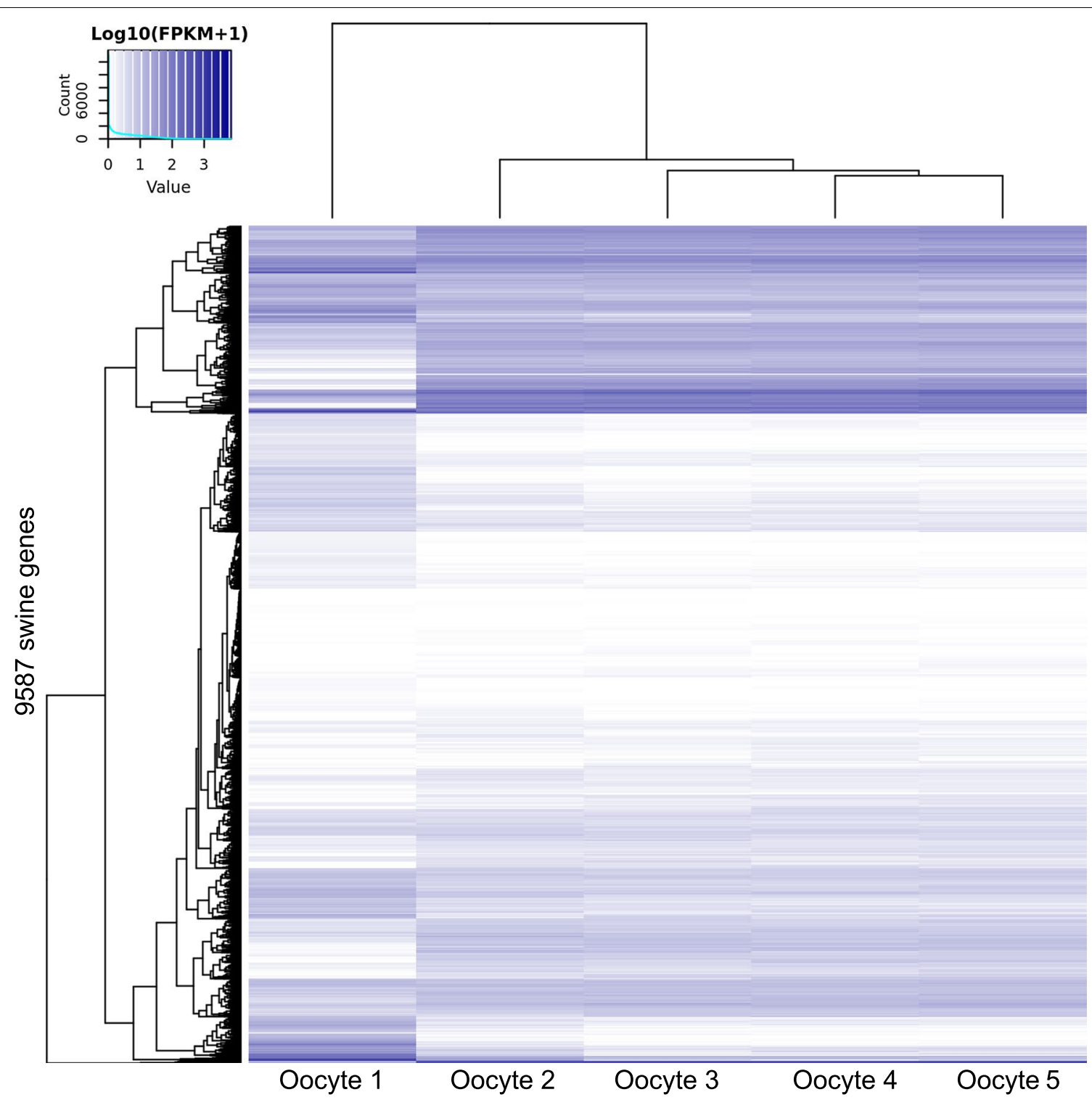

Fig. 2 Heatmap of the genes expressed in single oocytes 


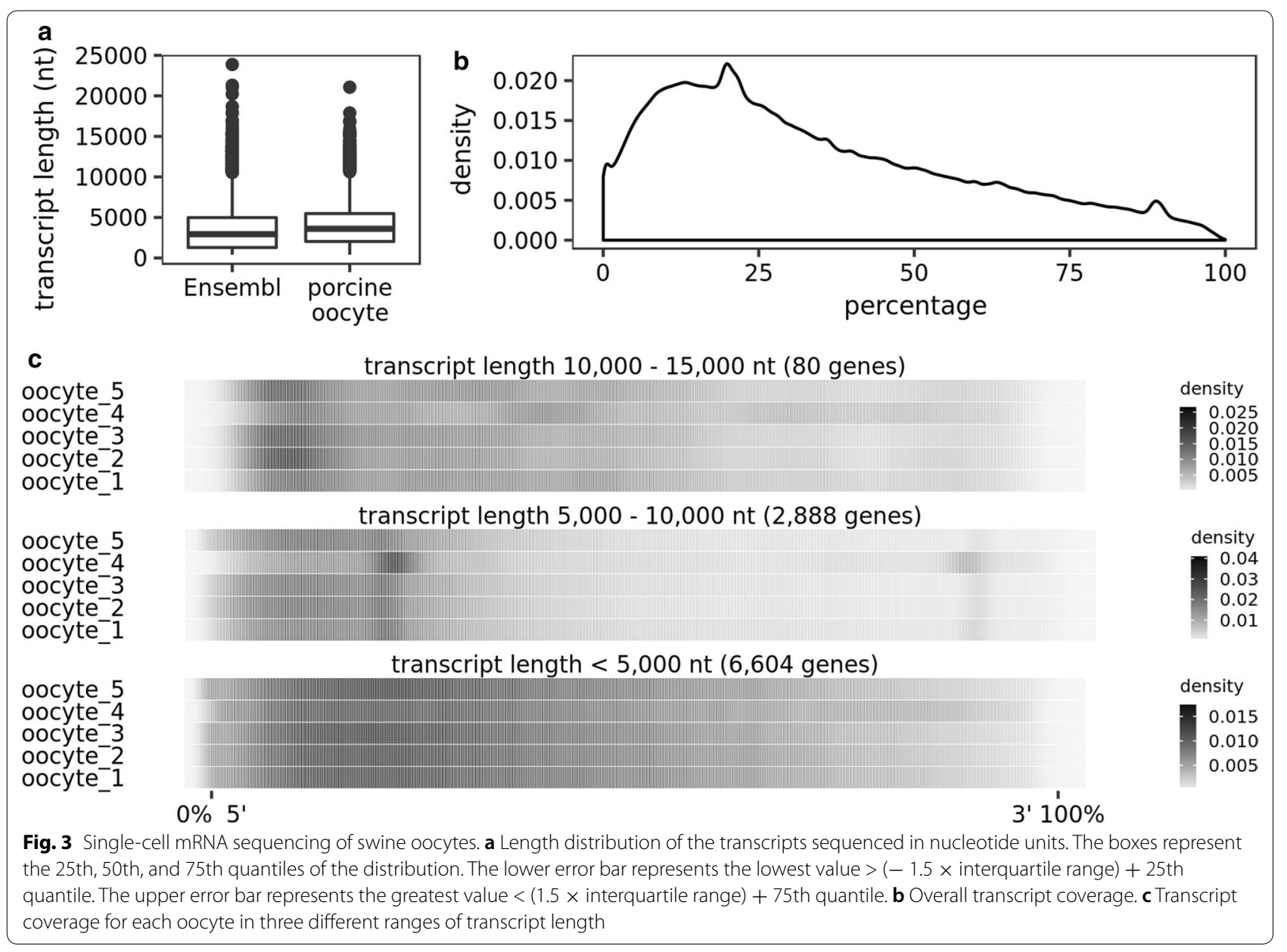

$122 \mathrm{nt}$ in the bovine and swine oocytes, respectively. The observations were consistent with the RNA length of the $5 \mathrm{~S}$ ribosomal subunit [16].

Amplification of polyA + RNA via polymerase chain reaction resulted in amplified cDNA (acDNA) products detected between $\sim 500$ and $\sim 5000$ nucleotides (Fig. 1d). The acDNA was used as input for library preparation and sequencing. We generated RNA-sequencing data from five swine single-oocytes averaging 9,680,369 pair-end reads. The alignment of the reads to the swine cDNA sequences resulted in of 9587 Ensembl genes detected in all five oocytes at with fragments per kilobase of transcript per million reads mapped $>0.3$ (Fig. 2, see Additional file 2 for the list of genes).

The RNA-sequencing data revealed the quantification of short and long transcripts in single swine oocytes with a distribution similar to the observed in the Ensembl transcriptome database (Fig. 3a) with approximately 75\% of the transcripts composed of $\leq 5000$ nucleotides. Overall, there was a skewed distribution of reads towards $5^{\prime}$ end of the cDNA (Fig. 3b), which was probably caused by the tagmentation step of library preparation [17]. This tendency, however, was more prominent on transcripts whose length ranged between 5000 and 10,000 nucleotides, while, transcripts with less than 5000 nucleotides presented a more homogeneous read distribution across the transcripts (Fig. 3c). Most importantly, the overall distribution of read coverage on the transcripts was reproducible across five oocytes sequenced (Fig. 3c).

We adapted the phenol-chloroform protocol to extract total RNA from single oocytes. Our adaptations to the phenol-chloroform protocol permit non-selective extraction of total RNA from single oocytes. The extracted RNA is compatible with downstream enzymatic assays required for the generation of single-cell mRNA sequencing data. The transcripts of 9587 swine genes were sequenced from single oocytes with nearly full coverage. 


\section{Limitations}

Due to the limited number of cells analyzed, this study captured a snapshot of the complexity existent in bovine and swine oocytes.

\section{Additional files}

Additional file 1. Extraction of total RNA from single-oocytes and singlecell mRNA sequencing of swine oocytes. This file contains the code used to generate Figs. 2 and 3 .

Additional file 2. Genes expressed in single porcine oocytes. This file contains the genes expressed in single porcine oocytes and the corresponding annotation.

\section{Abbreviations}

RNA: ribonucleic acid; rRNA: ribosomal ribonucleic acid; tRNA: transfer ribonucleic acid; DNA: deoxyribonucleic acid; mRNA: messenger ribonucleic acid; polyA+: polyadenylated; cDNA: complementary DNA; acDNA: amplified cDNA; nt: nucleotide; U: units; $\mu$ l: microliter.

\section{Authors' contributions}

FHB and KMK performed experiments, FHB analyzed data, FHB, KMK and SED interpreted the results and wrote the manuscript. All authors read and approved the final manuscript.

\section{Acknowledgements}

We thank Mr. Brian Anderson from the Swine Research and Education Center and Mr. Barney Wilborn from the Auburn University Lambert-Powell Meats Lab and their associates for the assistance in the collection of swine ovaries.

\section{Competing interests}

The authors declare that they have no competing interests.

\section{Availability of data and materials}

The datasets generated and/or analyzed during the current study are available from the corresponding author on reasonable request.

\section{Consent for publication}

Not applicable.

\section{Ethics approval and consent to participate}

The ovaries were obtained from slaughterhouses, according to the consent of the corresponding managers.

\section{Funding}

Not applicable.

\section{Publisher's Note}

Springer Nature remains neutral with regard to jurisdictional claims in published maps and institutional affiliations.

Received: 10 January 2018 Accepted: 21 February 2018 Published online: 27 February 2018
References

1. Biase FH, Martelli L, Puga R, Giuliatti S, Santos-Biase WKF, Fonseca Merighe GK, et al. Messenger RNA expression of Pabpnl1 and Mbd312 genes in oocytes and cleavage embryos. Fertil Steril. 2010;93:2507-12. https://doi. org/10.1016/j.fertnstert.2009.08.051.

2. Biase FH. Oocyte developmental competence: insights from cross-species differential gene expression and human oocyte-specific functional gene networks. OMICS. 2017;21(3):156-68. https://doi.org/10.1089/ omi.2016.0177.

3. Biase FH, Everts RE, Oliveira R, Santos-Biase WK, Fonseca Merighe GK, Smith LC, et al. Messenger RNAs in metaphase II oocytes correlate with successful embryo development to the blastocyst stage. Zygote. 2014;22(1):69-79. https://doi.org/10.1017/S0967199412000299.

4. Tang F, Barbacioru C, Wang Y, Nordman E, Lee C, Xu N, et al. mRNASeq whole-transcriptome analysis of a single cell. Nat Methods. 2009;6:377-82. https://doi.org/10.1038/nmeth.1315.

5. Xue Z, Huang K, Cai C, Cai L, Jiang C-Y, Feng Y, et al. Genetic programs in human and mouse early embryos revealed by single-cell RNA sequencing. Nature. 2013;500:593-7. https://doi.org/10.1038/natur e12364.

6. Biase FH, Cao X, Zhong S. Cell fate inclination within 2-cell and 4-cell mouse embryos revealed by single-cell RNA sequencing. Genome Res. 2014;24:1787-96. https://doi.org/10.1101/gr.177725.114.

7. Reyes JM, Chitwood JL, Ross PJ. RNA-Seq profiling of single bovine oocyte transcript abundance and its modulation by cytoplasmic polyadenylation. Mol Reprod Dev. 2015;82:103-14. https://doi.org/10.1002/ mrd.22445.

8. Yin XY, Cheng GH, Guo HY, Wang Q, Li YJ, Zhang H. Single cell transcriptome profiling revealed differences in gene expression during oocyte maturation in Haimen white goats. Genet Mol Res. 2017. https://doi. org/10.4238/gmr16019564.

9. Liu Q, Li Y, Feng Y, Liu C, Ma J, Li Y, et al. Single-cell analysis of differences in transcriptomic profiles of oocytes and cumulus cells at GV MI, MII stages from PCOS patients. Sci Rep. 2016;6:39638. https://doi. org/10.1038/srep39638.

10. Picelli S, Faridani OR, Björklund AK, Winberg G, Sagasser S, Sandberg R. Full-length RNA-seq from single cells using Smart-seq2. Nat Protoc. 2014:9:171-81. https://doi.org/10.1038/nprot.2014.006.

11. Schrader C, Schielke A, Ellerbroek L, Johne R. PCR inhibitors-occurrence, properties and removal. J Appl Microbiol. 2012;113(5):1014-26. https:// doi.org/10.1111/j.1365-2672.2012.05384.x.

12. Chomczynski P, Sacchi N. The single-step method of RNA isolation by acid guanidinium thiocyanate-phenol-chloroform extraction: twentysomething years on. Nat Protoc. 2006;1(2):581-5. https://doi.org/10.1038/ nprot.2006.83.

13. Langmead B, Salzberg SL. Fast gapped-read alignment with Bowtie 2. Nat Methods. 2012;9:357-9. https://doi.org/10.1038/nmeth.1923.

14. Ihaka R, Gentleman R. R: a language and environment for statistical computing. J Comput Graph Stat. 1995;5:299-314.

15. Cirera S. Highly efficient method for isolation of total RNA from adipose tissue. BMC Res Notes. 2013;6:472. https://doi. org/10.1186/1756-0500-6-472.

16. Smirnov AV, Entelis NS, Krasheninnikov IA, Martin R, Tarassov IA Specific features of $5 S$ rRNA Structure-its interactions with macromolecules and possible functions. Biochemistry-Moscow. 2008;73(13):1418-37. https:// doi.org/10.1134/s000629790813004x.

17. Gertz J, Varley KE, Davis NS, Baas BJ, Goryshin IY, Vaidyanathan R, et al. Transposase mediated construction of RNA-seq libraries. Genome Res. 2012;22(1):134-41. https://doi.org/10.1101/gr.127373.111. 